\title{
Qual a Função Sociopolítica da Matemática na Educação Financeira?
}

\author{
Angelo Fernando Fiori \\ Universidade Regional do Noroeste do Estado do Rio Grande do Sul - UNIJUÍ \\ Universidade Comunitária da Região de Chapecó - UNICHAPECÓ \\ an@unochapeco.edu.br

\section{Luci Marchiori dos Santos Bernardi} \\ Universidade Comunitária da Região de Chapecó - UNICHAPECÓ \\ lucib@unochapeco.edu.br
}

\begin{abstract}
Resumo
Este artigo objetiva analisar a matemática presente na Educação Financeira, sua função e implicação sociopolítica. Compreendendo a Educação Financeira enquanto processo histórico, percebe-se qual a intencionalidade da matemática por aquela difundida: condutora de ações de um sistema que cada vez mais alienador. A Matemática deve, porém, empoderar os sujeitos com ferramentas que lhes permitam questionar seu entorno, quebrando o vínculo com a ideologia da certeza e construindo uma Matemática próxima às realidades e libertadora. Preocupar-se com a função sociopolítica da Matemática perpassa pelas salas de aula, onde educadores e educandos possam criticamente desconstruir uma matemática mercadológica e reconstruí-la as vistas da inclusão de todos.
\end{abstract}

Palavras-chave: Consumismo. Educação Matemática Crítica. Ideologia da Certeza. Empowerment.

\section{What is the Sociopolitical Function of Mathematics in Financial Education?}

\begin{abstract}
This article has how objective analyze the mathematic present in the Financial Education, its function and implication sociopolitical. Comprising the Financial Education while historical process, perceives which the mathematic intentionality diffused by it: leading for system actions growing alienating. The Mathematics, but should, empower the subjects with tools that allow them question their surrounding and breaking the link with the ideology of certainty building a Mathematic nearest to the realities and liberating. Worry about with the sociopolitical Mathematic role, permeates the classes, where educators and educated may critically deconstruct a merchantability mathematic and rebuild it do some sightseeing the inclusion of all people.
\end{abstract}

Keywords: Consumerism. Mathematics Education Criticizes. Ideology of Certainty. Empowerment. 


\section{Introdução}

Quando a Educação Financeira (EF) chegou nas escolas do país, questionou-se de onde, como e porque vinha. Não se pensou qual era a matemática que ali estava e tão pouco o que se queria com ela e menos ainda se havia a possibilidade de interdisciplinarmente construí-la na escola. O fato é que a EF já é realidade em muitas escolas brasileiras.

Em uma sociedade de consumidores marcada pelas coisas a serem escolhidas e os que as escolhem (BAUMANN, 2008, p. 20), a Matemática desempenha um papel indispensável enquanto ferramenta de compreensão e ação, por permitir o desenvolvimento do raciocínio crítico quando mostra aos sujeitos a possibilidade de caminhos e a viabilidade de trilhá-los. Porém, a matemática que acabou se atrelando a EF, deu-lhe sustentação enquanto imperadora das ciências, contra a qual não há justificativa ou questionamentos, em suma, como traduz Skovsmose (2001), uma "linguagem do poder" a qual não é influenciada por nenhum interesse social, político ou ideológico e ainda cabendo a Matemática uma resposta plena e superior.

Ao objetivar-se analisar a função sociopolítica que a Matemática desempenha dentro da EF, propõe-se também debater e analisar a própria matemática e a forma como é ensinada. Para esta discussão este artigo se caracteriza enquanto uma investigação qualitativa através de pesquisa bibliográfica. Segundo Borba e Araújo (2006), o qualitativo engloba a ideia de subjetivo, passível de expor sensações e opiniões, engloba ainda noções de respeito a diferenças e semelhanças. Com base no objetivo, caracteriza-se enquanto uma pesquisa exploratória com coleta de dados indireta.

De modo por atender o objetivo proposto, este trabalho estrutura-se em contextualizar historicamente a EF, discutir a matemática presente na EF analisando seu papel social, político e econômico, buscando estabelecer contrapontos entre a Educação Financeira e a função sociopolítica da Matemática, à luz de contribuir na construção de uma Educação Financeira Crítica.

\section{De onde vem a Educação Financeira?}

Apesar de ser uma discussão relativamente recente na educação escolar, a EF está presente nas relações sociais desde quando se houve a necessidade de não mais trocar mercadorias por outras e sim, estabelecer uma moeda de troca quase que unanime: o dinheiro. O dinheiro está, segundo Moreira (2000), impregnado na vida social dos sujeitos em todas as esferas e destes faz distinção, aliena e empodera.

Durante a história da humanidade, os diversos regimes e momentos econômicos que se instauraram, sempre separaram aqueles que têm daqueles que não tem dinheiro, de modo que se constituiu uma sociedade consumidora, a ponto do capital anteceder o sujeito: "ninguém se torna sujeito sem primeiro virar mercadoria" (BAUMANN, 2008, p. 20). No entanto, esqueceu-se que 
representavam em si, seres humanos com as mesmas potencialidades inseridos em uma sociedade de classes que os discriminava e lhes colocava em uma situação de explorador e explorado.

Com o capitalismo, o dinheiro tomou força e impulsionou, sob a bandeira da possibilidade de igualdade, falácias sociais e econômicas quase irreversíveis. Contudo, a alta produtividade do período foi acompanhada pela padronização de mercadorias e o aumento dos ganhos salariais, fomentando assim o consumo. (DIAS; SILVA NETO, 2004). A remuneração era necessária até mesmo para manter o ciclo de capital, gerando demanda para a produção e aumento cada vez maior pela necessidade do ter.

O século XX representou um contraponto ao modelo capitalista vigente. Crises de oferta e demanda como a de 1929, bem como a recuperação de uma guerra e o início de uma segunda, além das diversas batalhas que ocorreram neste período contribuíram para caracterizar um novo tipo de mercado onde os

[...] setores da economia fora da produção de bens de consumo estão, de modo crescente, sendo arrastados para o modelo dos bens de consumo e para a matriz de consumismo, e estão sob pressão para 'empacotar' suas atividades como bens de consumo seus serviços precisam se curvar ao poder dos 'consumidores'. (FAIRCLOUGH, 2001, p.151).

Mesmo assim, até meados da década de setenta, havia certo controle quanto a movimentação do capital. De acordo com Lapyda (2011, p.7) “[...] aumento exponencial das transações tanto em termos absolutos, como em relação às atividades produtivas; a liberação e desregulamentação de mercados e das atividades financeiras em todo mundo; [e] o surgimento de novos agentes e instituições ligadas às finanças" eram características muito presentes nesta fase, além da retomada de uma economia neoliberal e agora globalizada.

Para Manfredini (2007), as transformações na forma de usar o dinheiro influenciam diretamente na EF como um todo, pois munidos de salário, disponibilidade e variedade de produtos e serviços, as pessoas se tornaram cada vez mais consumidoras. E, com facilidades e comodidades também aumentando, as pessoas se perderam na administração de tais fatores e acabaram por se endividar o que não é bom nem para as famílias nem para o país.

Preocupados com o crescente endividamento de suas populações, os trinta e quatro países membros da Organização para Cooperação e Desenvolvimento Econômico (OCDE) ${ }^{1}$ incluíram em 2003, a EF na pauta de discussões, buscando mobilizar os países, membros ou não, para que

\footnotetext{
${ }^{1}$ OCDE é uma organização que tem por missão a promoção de políticas que melhorem o bem-estar econômico e social das pessoas. Para isso estabelece padrões globais para assuntos ligados a economia e que afetam diretamente a vida cotidiana. Está ligada à empresas, sindicatos e instituições da sociedade civil. Informações disponíveis em: $<$ http://www.oecd.org/about/>. Acesso em: 07 mar. 2014.
} 
educassem financeiramente seus cidadãos. A primeira ação se dá através do Projeto de Educação Financeira, aprovado por uma comissão da OCDE, que propõe um estudo internacional do tema.

Tal projeto identificou e analisou as propostas e pesquisas sobre EF nos países membros da OCDE, descrevendo os distintos programas existentes e a sua eficácia, e em seu relatório apontou, segundo Silva e Powell (2011), três pontos importantes quanto aos cidadãos analisados: contabilizou a existência de um número crescente de trabalhadores que contariam com pensões e economias pessoais para financiar a sua aposentadoria; constatou que muitos consumidores, de modo especial os jovens, se endividavam pela maneira com que lidam com os objetos de crédito (cartões, por exemplo); e, finalmente, o indicou uma certa contradição: se por um lado havia um crescimento no número de operações financeiras em meios eletrônicos, fora constatado em vários países que uma porcentagem significativa de consumidores não participa do sistema financeiro (não tem contas bancárias, por exemplo).

Assim como a OCDE, os interessados pela EF, de modo geral, são instituições financeiras, empresas e profissionais que estão mais ligados ao capital. Desta forma, é possível observar que os propósitos preconizados estão voltados para a formatação do consumo e da poupança.

As propostas até então veiculadas no meio educacional e social em geral, quando ocorrem, no sentido de propiciar cidadania, vêm surgindo com mais intensidade nas esferas empresariais, de instituições financeiras, com aparente interesse em alfabetizar economicamente os indivíduos consumidores. (KISTEMANN JÚNIOR, 2011, p. 107).

Neste contexto, conceitos de "gerir a renda, poupar e investir", permearam todo um conceito internacional enraizado nas legislações e nas práticas dos educandos e educadores financeiros.

A velha sociedade moderna engajava seus membros primordialmente como produtores e soldados [...]. A norma que aquela sociedade colocava para seus membros era a capacidade e a vontade de desempenhá-los. Mas o atual estágio, pós-moderno, a sociedade moderna tem pouca necessidade de mão de obra industrial em massa e de exércitos recrutados; em vez disso precisa engajar seus membros pela condição de consumidores. (BAUMAN, 1999, p. 88).

Nesta nova organização social, cada dia mais presente, a Matemática tem papel fundamental por representa a possibilidade de organização e questionamento em ações que auxiliem as pessoas na tomada de decisão e do pensamento crítico frente seu dinheiro. 


\section{Educação Financeira: conceitos e conteúdos}

Dado que a OCDE, bem como os interessados pela EF, de modo geral, são instituições financeiras, empresas e profissionais que estão vinculadas à produção e ao controle do capital, o conceito de EF por estes instituído está com foco no produto financeiro e suas relações com o consumo e o investimento individual.

Em seu relatório, a OCDE trata a Educação Financeira como indispensável em todos os momentos, servindo aos consumidores "para auxiliá-los a orçar e gerir a sua renda, a poupar e investir, e a evitar que se tornem vítimas de fraudes" (OCDE, 2004, p. 223). Ainda para a OCDE, a Educação Financeira

[...] é o processo pelo qual os consumidores financeiros/investidores melhoram a sua compreensão sobre os conceitos e produtos financeiros e, através da informação, instrução e/ou aconselhamento objetivos, desenvolvam as habilidades e a confiança para tomar consciência de riscos e oportunidades financeiras, para fazer escolhas informadas, saber onde buscar ajuda e tomar outras medidas eficazes para melhorar a sua proteção e o seu bem-estar financeiro. (OCDE, 2005, p. 4, tradução própria).

Muitos autores colocam a EF como ferramenta indispensável na construção da qualidade de vida. Sua definição, de modo geral, compreende todas as estratégias que o indivíduo tem para com seu dinheiro, buscando satisfazer suas necessidades. Para Mundy (2008) a EF deve ajudar as pessoas a administrar bem o seu dinheiro durante a vida através de atitudes, comportamentos, conhecimentos e habilidades. E, caso o sujeito não se torne financeiramente capaz, de nada serviu a educação recebida. Acompanhando este autor, Braunstein e Welch (2002) expandem este conceito e ao mesmo tempo restringem bem os envolvidos, dizendo que os 'participantes', quando estão bem informados sobre o mercado, contribuem para a eficiência e a competitividade, haja vista que quando os consumidores estão conscientes geram um processo de consumo mais condizente com as necessidades, forçando os provedores financeiros a criar condições aos consumidores para adquirirem seus produtos.

Para Baumann (2001), uma sociedade consumidora rejeita qualquer outra opção e encoraja o consumismo. Neste processo, os membros da sociedade perdem sua identidade (consumidores, participantes, investidores e outras tantas denominações) e são massificados, refletindo diretamente na forma da construir políticas públicas e em especial naquelas que norteiam a educação básica como um todo, pensando apenas no todo, no amplo e não no indivíduo.

Acompanhando tal tendência, o Brasil aprovou em 2010 sua Estratégia Nacional de Educação Financeira (ENEF) que, em seu artigo primeiro, salienta que esta "tem por finalidade promover a educação financeira e previdenciária e contribuir para o fortalecimento da cidadania, a eficiência e solidez do sistema financeiro nacional e a tomada de decisões conscientes por parte dos 
consumidores" (BRASIL, 2010), ou seja, uma política que projeta um ideal de massa, onde o fim último é a solidez da economia e o consumo. Também, como ocorre na maioria dos países, as ações da estratégia focam nas escolas. Para isso foi instituído, através de legislação, o Comitê Nacional de Educação Financeira (CONEF) o qual possui participação quase inexpressiva do ministério da educação.

Nas escolas brasileiras a questão financeira antecede a proposição da ENEF. Em 1998, os Parâmetros Curriculares Nacional (PCN) já preconizavam em suas orientações, a Matemática Financeira como uma aplicação da Matemática, promovendo a autonomia nas decisões em situações do cotidiano, possibilitando aos educandos pesquisarem e ampliarem seus conhecimentos sobre o assunto (BRASIL, 1998b). Mas sem dúvida o que se pode ressaltar, enquanto relevante para o presente estudo, é o fato dos PCN + (PCN Mais Ensino Médio), apontarem para uma escola que auxilie os educandos e suas famílias que estão "economicamente marginalizadas ou apartadas de participação social. A escola de ensino médio pode constituir uma oportunidade única de orientação para a vida comunitária e política, econômica e financeira, cultural e desportiva” (BRASIL, 1998a, p. 12). Para isso, a escola deve buscar analisar os problemas reais no sentido financeiro, tecnológico ou social, ampliando assim sua atuação quanto à aplicação do dinheiro.

A partir dos diversos conceitos da EF, se faz necessário que existam conteúdos fundamentais a serem construídos em sala ou fora dela. Assim, a ENEF define em seu plano diretor, deliberado pelo CONEF, alguns eixos nacionais e que devem ser preferencialmente contemplados segundo a ENEF (2011). São eles: planejamento financeiro, economia, serviços financeiros, crédito e juros, investimentos, previdência social, seguros, capitalizações e por fim a proteção e defesa do consumidor.

A sugestão do CONEF é que a EF seja, assim como Meio Ambiente, Saúde, Ética, Orientação Sexual, Pluralidade Cultural, Trabalho e Consumo, um tema transversal, independentemente da área, seja Matemática, História, Arte, Ciências Naturais ou Língua Portuguesa, que esteja presente nas discussões. Desta forma a EF perpassa por diferentes disciplinas curriculares da Educação Básica.

Se quer um movimento mais profundo, uma EF para além do capital, discutida nas diversas áreas. Como apontado por Chiarello (2014), a EF traz muitas inquietações que fomentam o anseio de entender dimensões sociais, econômicas, políticas e culturais. Assim, a EF e a sua relação com o capitalismo, o consumismo e o consumo, precisa também tencionar as relações com a sociedade, as questões ambientais, salariais, de classes sociais e desigualdades. Na esteira desse debate, quer se discutir a questão da matemática como elemento formativo na EF. 


\section{E a Matemática? Qual é sua função sociopolítica?}

A Educação Matemática (EM) tem ocupado um lugar de destaque na medida em que se preocupa com diferentes questões que envolvem a matemática, o seu ensino, o seu uso, as relações de poder existentes. Diversos conceitos de matemática, básicos ou mais elaborados, podem ser desenvolvidos nas dimensões propostas pela EF, dentre os quais se podem destacar regra de três, funções, sequências e progressões, probabilidade e estatística. Tais conteúdos se bem compreendidos auxiliam, e muito, na análise da situação e do comportamento futuro. Cabe, na verdade, refletir sobre como tais conteúdos podem ser potencializados na EF e no comportamento dos que deles se utilizam.

Dado que, segundo Freire (2005) o conhecimento é uma construção social, considera-se importante fomentar debates acerca do poder, dos aspectos sociopolíticos da matemática, e ainda, é necessário questionar

[...] a quem interessa que a educação matemática seja organizada dessa maneira? Para quem a educação matemática deve estar voltada? Como evitar preconceitos nos processos analisados pela educação matemática que sejam nefastos para grupos de oprimidos como trabalhadores, negros, índios e mulheres? (SKOVSMOSE, 2001, p. 7).

Conforme lembra Skovsmose (2001) a questão central, não é a Matemática em si, mas o ideal de, ao aplicar-se um conjunto de regras lógicas e criteriosas, obtém-se sempre a solução aos problemas. Sendo assim, a função sociopolítica da Matemática pode ser resumido na possibilidade de incluir ou excluir, na possibilidade de discutir ou compactuar. Em conformidade, Matos (2005, p.2) destaca que:

[...] o ensino da matemática tem tido em muitos países uma função social de diferenciação e de exclusão. A matemática é tipicamente um mistério para muita gente e tem-lhe sido oferecido o papel de juiz pseudo-objectivo, que decide quem está apto e quem está inapto na sociedade, rotulando e posicionando as crianças, os jovens e os adultos como aptos ou como inaptos, e por isso tem servido como um dos guardiões do direito de participação nos processos de decisão da sociedade.

Matemática exerce um poder tão grande quanto invisível. Os educandos que não aprendem Matemática estão, segundo Melin-Olsen (1987) e Volmink (1989) (apud SKOVSMOSE, 2001), em desvantagem, já que não serão capazes de lidar com a complexidade da sociedade atual. Além disso, usar incorretamente a Matemática leva à discriminação racial, sexual e socioeconômica na sociedade. A Matemática se torna frequentemente segundo Skovsmose (2001, p 129) "uma referência 'acima de tudo', como um 'juiz', que está acima dos seres humanos, como artifício nãohumano que pudesse controlar a imperfeição humana.”. 
Um caminho para romper essa ideologia é reconhecer a Matemática enquanto processo contínuo e dinâmico e, mais do que isso, como um processo de potencializar os educandos frente a sua realidade, uma EM para o empowerment ${ }^{2}$. Muitos termos foram criados para ressaltar esse potencial. No entanto, Skovsmose (2008) prefere utilizar o termo matemacia para indicar o caráter crítico da EM e restringe o seu significado, "apontando como noções de confiabilidade e de responsabilidade podem ser tratadas no âmbito da educação matemática" (p.123). A noção de matemacia é um tanto complexa e aproxima-se da literácia de Freire (1984), referindo-se à capacidade que transcende o saber Matemática e o perpassa por compreendê-lo e utilizá-lo de modo a tornar o sujeito crítico e transformador de sua realidade.

Ao analisar o exposto nos documentos, é possível perceber que pouco se fala em posicionamento crítico dos envolvidos na $\mathrm{EF}$, o que demonstra uma tendência sutil em manter uma situação historicamente construída de um ensino para a alienação, que não oportuniza aos educandos um empoderamento para questionar, refletir e agir criticamente. Assim, é necessário pensar em como a matemática pode alienar as decisões ou mascarar fatores importantes, condicionando resultados nos temas propostos na $\mathrm{EF}$, questionar qual o papel sociopolítico da matemática para a formação desses educandos, para a construção de uma EF dialética e reflexiva, buscando torná-la instrumento de transformação na mão dos envolvidos. Propõe-se pensar em que medida aprender EF contribui efetivamente com o empoderamento do educando.

\section{Educação Financeira Crítica enquanto caminho}

A construção de uma EF voltada para a formação de sujeitos críticos perpassa pelas salas de aula e pelas aulas de Matemática. É importante que o educador esteja atento e empenhado em verdadeiramente assumir este desafio. Se quer uma EF como um conjunto de instrumentos que auxiliem as pessoas na compreensão e na utilidade do dinheiro em suas vidas, fazendo deste, instrumento de promoção de justiça social e crescimento sustentável a todos, sem distinção de poder econômico ou condição social, reconstruindo, assim, uma sociedade solidária e preocupada com o seu futuro.

A possibilidade de tratar a EF enquanto tema transversal ou mesmo de utilizar o ensino de Matemática como prática emancipatória deve cotidianamente fortalecer a Matemática e a EF em seu sentido questionador e crítico. Além disso, uma prática que conduza os educandos para uma sociedade mais engajada na promoção de igualdade perpassa obrigatoriamente por uma EF

\footnotetext{
2 Devido a ampla gama de significados da palavra empowerment (dar poder a; ativar a potencialidade criativa; desenvolver a potencialidade criativa do sujeito; dinamizar a potencialidade do sujeito), os tradutores optaram por utilizar a palavra no original e em itálico, neste trabalho porém ela está em formato corrente ao texto. Skovsmose também utiliza o termo assim, quando apresenta seus trabalhos em português.
} 
preocupada em apresentar o dinheiro e os bens enquanto instrumento de ação no mundo. Assim, destacam-se dois contrapontos muito fortes entre a EF e a função sociopolítica da Matemática.

$\mathrm{O}$ primeiro refere à constante analogia com o meio empresarial e de instituições financeiras. Objetiva-se, segundo os documentos oficiais, propiciar a cidadania e a compreensão de conceitos e produtos financeiros, mas quando se atrela a isso instituições e empresas na verdade se quer restringir e valorizar determinados cartéis que dominam o cenário econômico e financeiro nas mais diversas esferas, fortalecendo um grupo e algumas ideologias. A matemática que está ali presente se torna a certeza e o instrumento pelo qual tais instituições e empresas alienam a população que deles precisa. Não pode o educador em sala de aula querer que seus educandos aceitem a Matemática e seus resultados como absolutos, mas que se utilizem dela para, criticamente, tomar suas decisões financeiras. Logo, a Matemática deve exercer seu empoderamento no sentido mais libertador possível, munindo os educandos de instrumentos que lhes permitam perceber a sutileza da Matemática utilizada pelas instituições financeiras em seus instrumentos de estudo, os quais, sendo utilizados nos espaços de estudo da EF, servem para promovê-las, enquanto preocupadas com a situação financeira, ao mesmo tempo em que disparam estratégias de marketing e difusão de ideologias que, de modo algum, desejam que aqueles que delas se utilizam se desliguem do processo do capital.

O segundo ponto trata da massificação através de estratégias de consumo, pelas quais se deixa de ser pessoas humanas, tornando-se meros consumidores. Ou seja, o que se quer é que se consuma, independentemente do que e da necessidade ou desejo de determinado produto ou serviço. De maneira semelhante se ensina Matemática. Deseja-se que, independentemente do conteúdo, da necessidade ou do desejo do educando em aprendê-lo, este o receba (educação bancária) e o compreenda. E ainda, para reforçar, utiliza-se atividades de memorização e repetição de algoritmos. Não se pode pensar em uma EF se não for feita uma mínima contextualização da situação, atentando especialmente para fatores sociais e sustentáveis. Não se pode tão somente construir espaços de mera repetição, mas valorizar meios críticos de debate afim de oportunizar inquietações e ações dos educandos na sua realidade. A matemácia a ser construída juntamente com a EF necessita refletir e agir criticamente frente à ótica do dinheiro. E isso é papel do educador matemático e seus educandos, rompendo com a condição de consumidores que o mercado necessita para manter o status do dinheiro e de sua importância social.

Partindo-se destes dois pontos é que se constrói o conceito de uma Educação Financeira Crítica (EFC) enquanto um conjunto de instrumentos que auxiliam as pessoas a compreender a utilidade do dinheiro em suas vidas, fazendo deste, instrumento de promoção de justiça social e 
crescimento sustentável a todos, sem distinção de poder ou condição, reconstruindo, assim, uma sociedade solidária e preocupada com o seu futuro.

Enfim, uma EFC que rompa ou minimamente questione a situação econômica, social e política dos sujeitos, deve auxiliar na reconstrução de toda a sociedade enquanto preocupando-se com as mais diversas esferas sem esquecer-se de suas implicações diretas e indiretas. A matemática pode servir como importante aliada, desenvolvendo com os educandos uma postura ética e cidadã, mas por primazia, libertadora.

\section{Referências}

BAUMAN, Zygmunt. Globalização: as consequências humanas, RJ: Zahar, 1999.

$\overline{\text { Zahar, } 2008 .}$

. Vida para o Consumo: a transformação de pessoas em mercadorias. Rio de Janeiro:

BORBA, Marcelo de Carvalho; ARAÚJO, Jussara de Loiola (Org.) Pesquisa qualitativa em educação matemática. 2.ed. Belo Horizonte: Autêntica, 2006.

BRASIL, Decreto n. 7.397 de 22 dez. de 2010. ENEF: Estratégia Nacional de Educação Financeira. Publicada no diário Oficial da União em 23 dez. 2010. Disponível em:

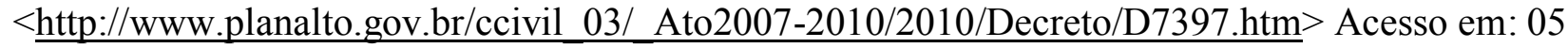
nov. 2013.

BRASIL, Parâmetros Curriculares Nacionais Mais Ensino Médio: orientações educacionais complementares aos parâmetros curriculares nacionais. 1998a. Disponível em:

$<$ http://portal.mec.gov.br/seb/arquivos/pdf/CienciasNatureza.pdf>. Acesso em: 12 nov. 2013.

BRASIL, Parâmetros Curriculares Nacionais: matemática. 1998b. Disponível em:

$<$ http://portal.mec.gov.br/seb/arquivos/pdf/matematica.pdf> $>$. Acesso em: 12 nov. 2013.

BRAUNSTEIN, Sandra; WELCH, Carolyn. Financial literacy: an overview of practice, research, and policy. Federal Reserve Bulletin, Nov. 2002. Disponível em:

<http://www.federalreserve.gov/pubs/bulletin/2002/1102lead.pdf> . Acesso em: 13 ago. 2013.

CHIARELLO, Ana Paula Rohrbek. Educação financeira crítica: novos desafios na formação continuada de professores. Dissertação de Mestrado. (Programa de Pós-graduação stricto sensu em Educação). 147 p. Universidade Comunitária da Região de Chapecó, Chapecó SC, 2014.

DIAS, Robson Santos; SILVA NETO, Romeu e. Uma análise das transformações espaciais decorrentes da passagem do regime fordista para os regimes flexíveis de acumulação. Vértices. v. 6, n. 2, p 9-38, mai/ago 2004. Disponível em:

$<$ http://www.essentiaeditora.iff.edu.br/index.php/vertices/article/view/1809-2667.20040008/92>.

Acesso em: 14 ago. 2013.

ENEF. Plano diretor. 2011. Disponível em:

$<$ http://www.vidaedinheiro.gov.br/Imagens/Plano\%20Diretor\%20ENEF.pdf $>$. Acesso em: 12 nov. 2013.

FAIRCLOUGH, Norman. Discurso e mudança social. Brasília: UnB, 2001.

FREIRE, Paulo. A importância do ato de ler em três artigos que se completam. 6 ed. São Paulo: Autores Associados, 1984.

. Pedagogia do oprimido. 41 ed. São Paulo: Cortez, 2005. 
KISTEMANN JÚNIOR, M. A. Sobre a produção de significados e a tomada de decisão de indivíduos-consumidores. Tese de Doutorado. (Programa de Pós-graduação em Educação Matemática), Instituto de Geociências De Ciências Exatas, Campus de Rio Claro, Universidade Estadual Paulista, Rio Claro, 2011. Disponível em:

$<$ http://www.athena.biblioteca.unesp.br/exlibris/bd/brc/33004137031P7/2011/kistemannjunior ma dr rcla.pdf $>$. Acesso em: 14 ago. 2013.

LAPYDA, Ilan. A "financeirização" do capitalismo contemporâneo: uma discussão sobre as teorias de François Chesnais e David Harvey. 223 f. Dissertação (Mestrado em Sociologia). São Paulo, 2011. Disponível em: $<$ http://www.teses.usp.br/teses/disponiveis/8/8132/tde-30092011095732/pt-br.php $>$. Acesso em 14 ago. 2013.

MANFREDINI, Andreza Maria Neves. Pais e filhos: um estudo da educação financeira em famílias na fase de aquisição. 2007. (Dissertação em Psicologia Clínica) - Pontifícia Universidade Católica de São Paulo, São Paulo.Disponível em:

$<$ http://www.dominiopublico.gov.br/download/texto/cp040678.pdf $>$. Acesso em: 13 ago. 2013.

MATOS, João Filipe. Matemática, educação e desenvolvimento social: questionando mitos que sustentam opções actuais em desenvolvimento curricular em matemática. 2005. Disponível em: $<$ www.educ.fc.ul.pt/docentes/jfmatos/comunicacoes/jfm seminario pa.pdf $>$. Acesso em: 18 out. 2014.

MOREIRA, Alice da Silva. Valores e dinheiros: um estudo transcultural das relações entre prioridades de valores e significado do dinheiro para indivíduos. Tese de Doutorado. (Doutorado em Psicologia), Universidade de Brasília, Instituto de Psicologia, 2000.

MUNDY, Shaun. Financial education programmes in school: analysis of selected current programmes and literature draft recommendations for best practices. OCDE journal: General papers, volume 2008/3. OCDE, 2008.Disponível em:

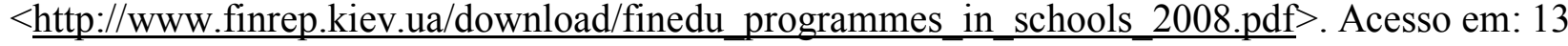
ago. 2013.

OCDE (Organização de Cooperação e de Desenvolvimento Econômico). Financial Education Project. Assessoria de Comunicação Social, 2004. Disponível em:

$<$ http://www.oecd.org/daf/financialmarketsinsuranceandpensions/financialeducation/33865427.pdf

>. Acesso em: 14 ago. 2013.

. Recommendation on principles and good practices for financial education and awareness. 2005. Disponível em:

$<\underline{\text { http://www.oecd.org/finance/financialeducation/35108560.pdf }}>$. Acesso em: 13 ago.2013.

SILVA, Amarildo Melchiades da; POWELL, Arthur Belford. Uma experiência de design em educação matemática: o projeto de educação financeira escolar. 2011. 16p. Projeto de Pesquisa (Estágio Pós-Doutoral em Educação Matemática) - Rutgers, the State University of New Jersey/ USA.

SKOVSMOSE, Ole. Desafios da reflexão em educação matemática crítica. Campinas - SP: Papirus, 2008.

2001.

Educação matemática crítica: a questão da democracia. Campinas-SP: Papirus, 